\title{
Creep properties of aluminium processed by ECAP
}

\author{
P. Král ${ }^{1,2 *}$, J. Dvořák ${ }^{1,2}$, A. Jäger ${ }^{3}$, M. Kvapilová ${ }^{1,2}$, Z. Horita ${ }^{4}$, V. Sklenička ${ }^{1,2}$ \\ ${ }^{1}$ Institute of Physics of Materials, ASCR, Žižkova 22, 61662 Brno, Czech Republic \\ ${ }^{2}$ CEITEC - IPM, Institute of Physics of Materials, ASCR, Žižkova 22, 61662 Brno, Czech Republic \\ ${ }^{3}$ Institute of Physics, ASCR, Na Slovance 2, 18221 Prague 1, Czech Republic \\ ${ }^{4}$ Department of Materials Science and Engineering, Faculty of Engineering, Kyushu University, 812-8581 Fukuoka, Japan
}

Received 25 May 2016, received in revised form 27 July 2016, accepted 2 August 2016

\begin{abstract}
The creep behaviour of pure polycrystalline aluminium and single crystals processed by equal-channel angular pressing (ECAP) was investigated in order to understand the relationships between heterogeneity of microstructure and creep behaviour. Tensile creep tests were performed at $373 \mathrm{~K}$ on specimens processed by 1 and 4 ECAP passes. For comparison purposes, the creep tests were also carried out on coarse-grained specimens. Microstructure analyses showed that application of ECAP technique on polycrystalline aluminium and single crystals led to the formation of significantly different microstructures even after a relatively high number of ECAP passes. The different creep behaviour of ECAP-processed single crystals and polycrystalline aluminium is influenced by inhomogeneity of microstructure. Further, the creep behaviour of specimens processed by 4 ECAP passes is affected by grain-boundary mediated processes like enhanced recovery of dislocations at high-angle grain boundaries in grains finer than quasi-stationary subgrain size and grain boundary sliding.
\end{abstract}

Key words: equal channel angular pressing (ECAP), aluminium, ultrafine-grained microstructure, creep

\section{Introduction}

The microstructure formed using severe plastic deformation (SPD) often results in an ultrafine-grained structure containing grains mainly with high-angle grain boundaries [1-4]. The sliding process in polycrystals is influenced by the presence of grain boundaries and crystallographic orientation of different grains. In single crystals, the dislocation glide is not blocked by grain boundaries due to only one crystallographic orientation at the beginning. Thus, in single crystals subjected to SPD, all grain boundaries are formed during deformation. To date, very limited experiments paid attention to the effect of initial crystallographic orientation on the evolution and mechanical properties of ultrafine-grained structure [5-9], but the most of the works on single crystals were concerned with processing only after 1 ECAP pass. It was suggested that the evolution of microstructure relates to the concentration of activated slip systems with respect to the shear plane.
Creep in polycrystalline materials after SPD processing was investigated on pure metals [10-16], alloys [17-20], and $\mathrm{Cu}-\mathrm{Al}_{2} \mathrm{O}_{3}$ composite [21]. However, there are a few reports documenting the creep properties and creep mechanisms of the ultrafine-grained (UFG) materials processed by different numbers of ECAP passes. On the basis of the stress dependences of the minimum creep rates, it was proposed [11-13] that the main operating creep deformation mechanism is an intragranular dislocation process with an additional mechanism(s) such as grain boundary sliding (GBS). Kawasaki et al. [22] demonstrated on the basis of texture measurements that creep occurs through an intragranular dislocation process with no significant contribution of diffusion creep. Blum et al. [10] suggested a model describing creep behaviour of UFG materials. This model explains creep behaviour on the basis of enhanced storage and recovery of dislocation at boundaries of grains finer than quasi-stationary subgrain size $w_{\mathrm{qs}}$ in the coarse-grained material [14, 23]. The quasi-stationary means that the dynamic

\footnotetext{
*Corresponding author: tel.: +420-532 290 368; fax: +420-541 218 657; e-mail address: pkral@ipm.cz
} 




Fig. 1. The orientation of $\{111\}$ planes in ECAP shear plane: (a) SCI and (b) SCII before ECAP. SD denotes the shear direction of ECAP deformation (normal direction

(ND) is perpendicular to TD and SD direction).

equilibrium of generation and recovery of free dislocations is approximately established in the microstructure, but the boundary structure is gradually evolving [23].

It was found $[24,25]$ that microstructure of ECAP materials after ECAP process and also after subsequent creep testing is inhomogeneous even after a high number of ECAP passes. However, the occurrence of inhomogeneity in the microstructure of ECAP specimens after creep testing and its influence on creep behaviour was not systematically studied.

\section{Experimental materials and procedures}

Experimental materials used in this investigation were polycrystalline $\mathrm{Al}$ and randomly oriented $\mathrm{Al}$ single crystals grown by modified Bridgman technique in a floating zone furnace. The single crystalline samples for ECAP were cut by electric discharge machining.

The crystallographic orientations of single crystals were determined using electron backscatter diffraction (EBSD). For the single crystal I (SCI), $\{\overline{1} 11\}$ was parallel to the theoretical shear plane of the ECAP die and $\langle 00 \overline{1}\rangle$ was parallel to the shear direction of ECAP process (Fig. 1a). For the single crystal II (SCII), $\{0 \overline{2} 1\}$ was parallel to the theoretical shear planes of the ECAP die and $\langle 100\rangle$ was parallel to the shear direction of ECAP process (Fig.1b).

The billets of SCs and polycrystalline Al were processed by ECAP at room temperature using a die hav-

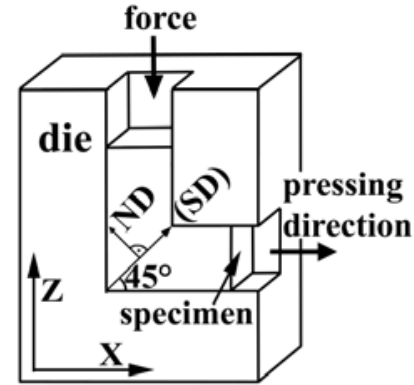

Fig. 2. Schematic illustration of ECAP die, coordinate system and pressing direction.

ing an internal angle of $90^{\circ}$ between the two parts of the channel and an outer arc of curvature of $\sim 20^{\circ}$. The billets were processed by route $\mathrm{A}$ for 1 and 4 ECAP passes, where the sample is pressed without rotation between sequential passes [3]. Here, route A was selected because the investigated section $X Z(X$ parallel to the last pressing direction and $Z$ perpendicular to the bottom of the channel) of samples is in the same position after 1 and 4 ECAP passes with respect to the position of the sides of ECAP die (Fig. 2). The chemical compositions of initial states are given in Table 1.

Constant load creep tests were performed in tension at $373 \mathrm{~K}$ under an initial applied stress of $50 \mathrm{MPa}$ for the SC samples and under different stresses for the unpressed coarse-grained and ECAPed polycrystalline Al. The tensile specimens, having a gauge length of $10 \mathrm{~mm}$ and cross-sectional area of $8 \times 3.2 \mathrm{~mm}^{2}$, were machined from billets parallel to the section $X Z$. The creep testing was conducted in an environment of purified argon with the testing temperatures maintained to within $\pm 0.5 \mathrm{~K}$ of the desired value. All of the tests were continued until fracture. The microstructure was examined by scanning electron microscope FEG-SEM Tescan equipped with EBSD. The microstructure analyses were performed on $3-5$ positions with investigated area usually $1.5 \times 10^{4} \mathrm{\mu m}^{2}$ $\left(150 \times 100 \mu \mathrm{m}^{2}\right)$ in each specimen. Grain boundaries measured by EBSD technique were classified into lowangle grain boundaries (LAGBs) with $\theta<15^{\circ}$ and high-angle grain boundaries (HAGBs) with $\theta \geq 15^{\circ}$ where $\theta$ is the misorientation angle between two neighbouring grains. The homogeneity of microstructure was described by the coefficients of profile area vari-

Table 1. Chemical composition of tested initial states (wt.\%)

\begin{tabular}{lcccccc}
\hline Specimen & $\mathrm{Fe}$ & $\mathrm{Si}$ & $\mathrm{Cu}$ & $\mathrm{Zn}$ & $\mathrm{Ti}$ & $\mathrm{Al}$ \\
\hline Polycrystalline Al & 0.0025 & $<0.01$ & 0.009 & 0.0022 & $<0.001$ & Bal. \\
SCI & 0.0022 & $<0.01$ & 0.011 & 0.0014 & $<0.001$ & Bal. \\
SCII & 0.0020 & $<0.01$ & 0.013 & 0.0023 & $<0.001$ & Bal. \\
\hline
\end{tabular}



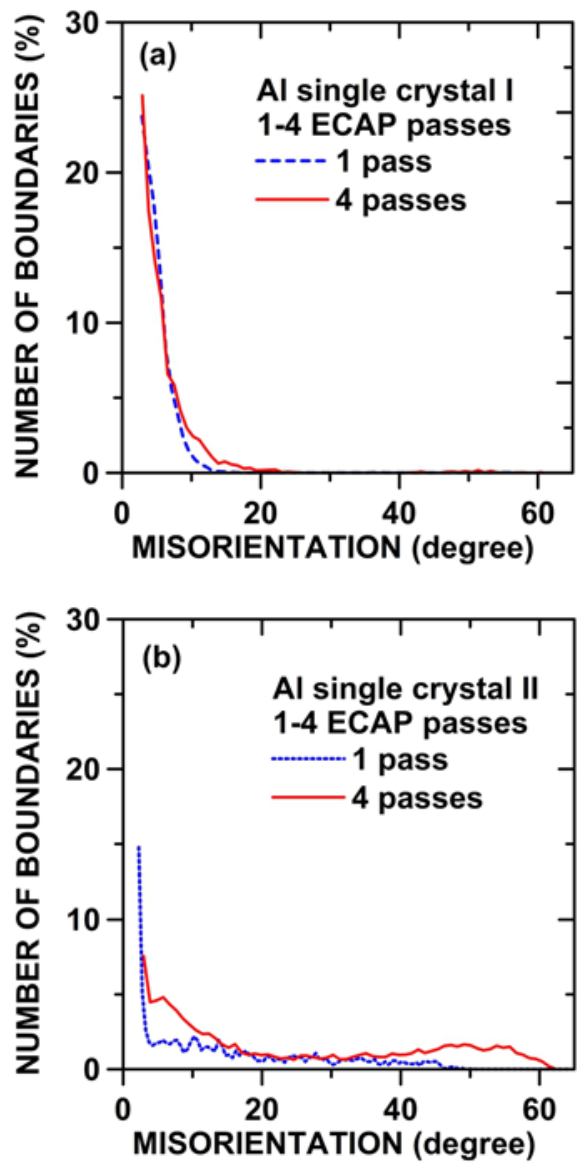

Fig. 3. Misorientation distribution of boundaries measured in the microstructure processed by 1 and 4 ECAP passes: (a) SCI and (b) SCII.

ation CVa: the higher are the values the more pronounced is the inhomogeneity. In homogeneous systems of grains $0.55 \leq \mathrm{CVa}<1$ holds, in mildly inhomogeneous systems is CVa lower than 2 and higher values are typical for systems with multimodal grain size distribution. A detailed description of $\mathrm{CV} a$ is given elsewhere $[24,25]$. The investigation was performed in the centre portion of the ECAP-processed single crystals in order to exclude frictional effects close to the sample surface. The local concentration of plastic deformation on grain boundaries and mesoscopic shear bands (MSBs) was qualitatively evaluated by displacement of the marker lines (scratches) transversal to the stress axis. The shear bands are called "mesoscopic" because their size exceeded significantly mean grain size measured in investigated specimens. But those shear bands do not usually extend along the whole diameter of the creep specimens. The displacements of the marker lines at their intersections with grain boundaries and MSBs were investigated using SEM.

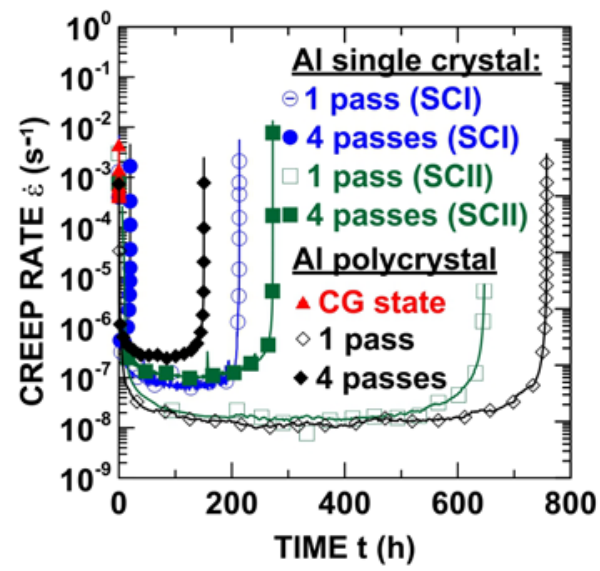

Fig. 4. Creep curves for investigated states of $\mathrm{Al}$ specimens processed by 1 and 4 ECAP passes.

\section{Experimental results}

\subsection{Microstructure of single crystals processed by $\mathrm{ECAP}$}

The microstructure of SCI processed by 1 ECAP pass contained mainly the subgrains with low-angle grain boundaries (Fig. 3a) and further ECAP deformation to 4 passes caused only a slight increase in HAGBs up to about $4.5 \%$.

As shown in Fig. 3b the ECAP-processed SCII contains relatively a high number of HAGBs (about $21 \%$ ) even after 1 ECAP pass. The further increase in the number of ECAP passes to 4 led to an additional increase in HAGBs with its frequency up to $\sim 52 \%$.

\subsection{Creep behaviour}

Representative creep curves for the single crystals and polycrystalline Al processed by 1 and 4 ECAP passes by route A are shown in Fig. 4. Inspection of Fig. 4 revealed that the minimum creep rate becomes higher and the time to the onset of accelerated creep becomes shorter as the number of ECAP pass is increased from 1 to 4 . This would be reasonable because the microstructure is refined with the number of ECAP passes and thus creep is accelerated by the lattice defects introduced by the ECAP process.

It was not experimentally feasible to compare creep behaviour of the single crystals processed by ECAP with unpressed single crystals because their creep resistances were too different to perform the creep tests at similar stress interval. Figure 5 shows the stress dependences of coarse-grained (CG) polycrystalline $\mathrm{Al}$ and the ECAP-processed $\mathrm{Al}$ after 4 passes, measured at the same creep rate interval.

The results demonstrate that the creep strength of the ECAP-processed $\mathrm{Al}$ is shifted to higher stresses in 


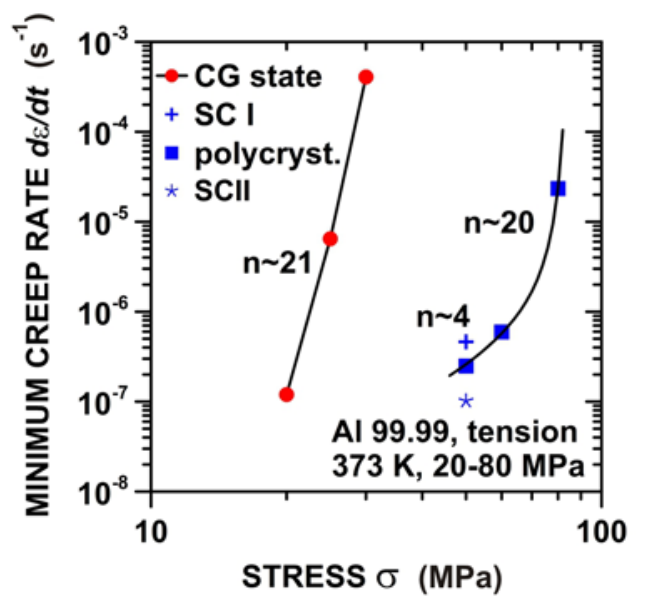

Fig. 5. Stress dependences of minimum creep rate for polycrystalline coarse-grained and aluminium processed by 4 ECAP passes.

comparison with the CG state. The stress exponent of the minimum creep rate $n$ for $\mathrm{CG} \mathrm{Al}$ is $\sim 21$ in the stress range covered in this study whereas $n$ is $\sim 4$ for the ECAP-processed $\mathrm{Al}$ after 4 passes at lower stresses.

\subsection{Microstructures of single crystals and polycrystalline Al after a creep exposure}

Figure 6 shows microstructures of SCI processed by 1 ECAP pass and subsequently creep tested at $373 \mathrm{~K}$, where Fig. 6a is taken from a gripping part and Fig. $6 \mathrm{~b}$ from a gauge part far away from the fracture tip. Both microstructures consist predominantly of LAGBs with a mean size of $\sim 1.6 \mu \mathrm{m}$ for the gauge part and of $\sim 2.5 \mu \mathrm{m}$ for the gripping part.

The microstructure of SCI after 1 ECAP pass and subsequent creep observed near the fracture tip is shown in Fig. 7a. In the microstructure near the fracture tip (necking area), $\sim 12.8 \%$ of HAGBs was measured, and they were located in particular at interfaces between a few shear bands (SBs) oriented near the shear planes of the first ECAP pass.

The EBSD analysis of the microstructure in SCI processed by 4 ECAP passes and creep exposure at $373 \mathrm{~K}$ demonstrates that HAGBs are formed in mesoscopic SBs (MSBs) (Fig. 7b). The MSBs were formed by groups of (sub)grains surrounded by boundaries with misorientations of $8^{\circ}-14^{\circ}$ which were coordinated near the shear plane of the last ECAP pass. The mean interboundary spacing of HAGBs was $\sim 10.5 \mu \mathrm{m}$ and the mean subgrain size in the MSBs was $\sim 2.3 \mu \mathrm{m}$. It was observed that 4 ECAP passes caused an only slight increase in the fraction of HAGBs and in the microstructure, it came to only $\sim 16.5 \%$.

The microstructure of SCII after 1 ECAP pass and
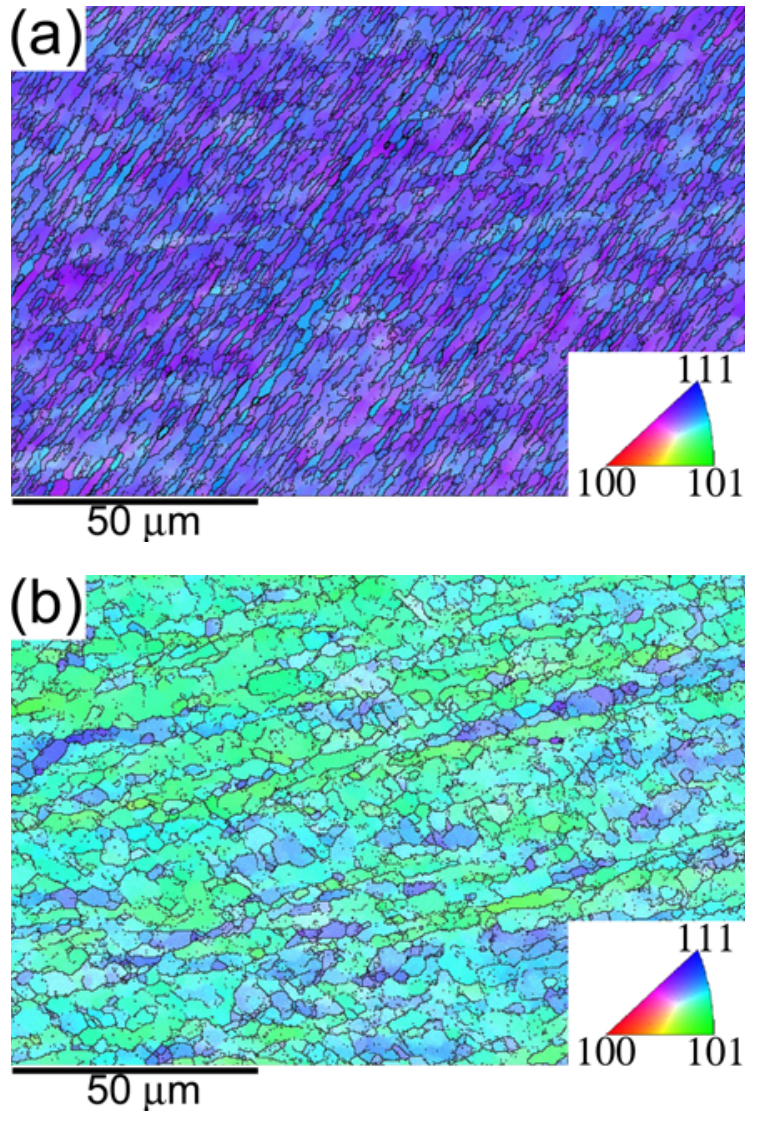

Fig. 6. The microstructure of SCI processed by 1 ECAP pass (inverse pole figures (IPF), normal direction): (a) gripping part and (b) gauge length. The stress axis is horizontal for all micrographs.

creep testing at $373 \mathrm{~K}$ is shown in Fig. 7c. Inspection of Fig. 7c revealed that microstructure is inhomogeneous and contained long MSBs approximately 30$40 \mu \mathrm{m}$ wide. The interior of MSBs was significantly different. The MSB (with an orientation of blue) contains in its interior subgrains with a mean size of $\sim 1.6 \mu \mathrm{m}$ and isolated grains with sizes from $\sim 1$ to $\sim 5 \mu \mathrm{m}$. The MSB (with an orientation of purple) contains only subgrains which are larger $(\sim 2.7 \mu \mathrm{m})$ than those in the neighbouring MSBs (Fig. 7c). At the interfaces of the MSBs, fine grains with sizes between $\sim 0.9$ $4.5 \mu \mathrm{m}$ were observed. In the microstructure, HAGBs were measured with a fraction of $\sim 13 \%$ and an interboundary spacing of $\sim 10 \mu \mathrm{m}$.

The microstructure of SCII processed by 4 ECAP passes and after a creep exposure was still heterogeneous (Fig. 7d). The microstructure contains long MSBs which consist of fine grains with sizes of $\sim 1-$ $5 \mu \mathrm{m}$ and subgrains with a mean size of $\sim 2.1 \mu \mathrm{m}$. In the interior of MSBs, there are areas which were partially surrounded by HAGBs. The long MSBs were separated by HAGBs approximately parallel to the stress axis and at their interfaces, grains or clusters of 

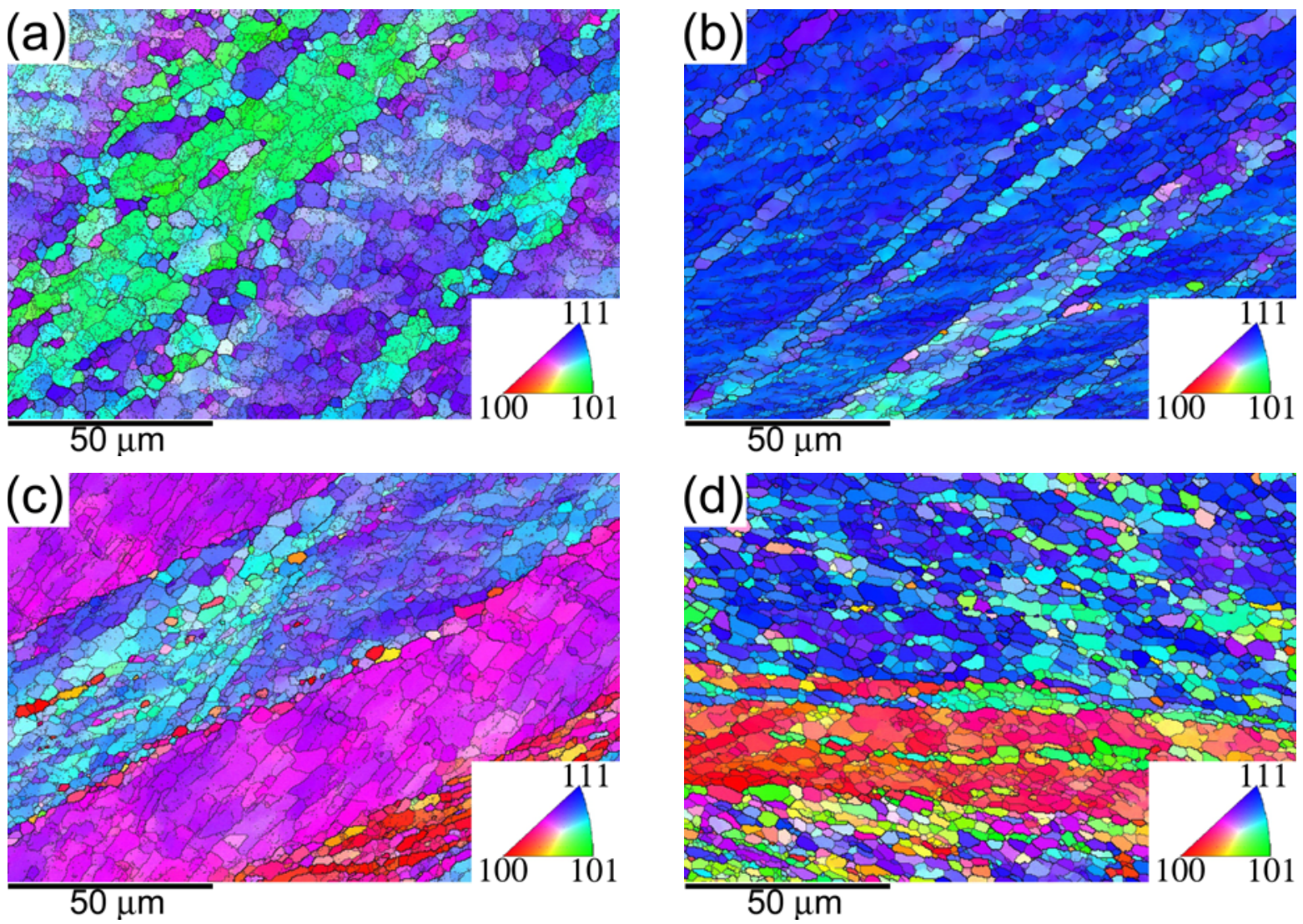

Fig. 7. The microstructure of single crystals after 1 and 4 ECAP passes and subsequent creep test at $373 \mathrm{~K}$ (IPF maps, normal direction) situated near the fracture (HAGBs are denoted by thick black line): (a), (b) SCI and (c), (d) SCII. The microstructures processed by 1 ECAP pass are placed in the left column (a), (c) and those by 4 ECAP passes are in the right column (b), (d). The stress axis is horizontal for all micrographs.

grains can be sporadically found. In the microstructure, HAGBs come to be a fraction of $\sim 39 \%$ and its interboundary spacing to be $\sim 4.6 \mu \mathrm{m}$.

LAGBs predominate in the microstructure of polycrystalline Al processed by 1 ECAP pass and subsequent creep testing at $373 \mathrm{~K}$ (Fig. 8a). However, polycrystalline $\mathrm{Al}$ processed by 4 ECAP passes and creeptested at $373 \mathrm{~K}$ contains $\sim 42 \%$ of HAGBs. Inspection of Fig. $8 \mathrm{~b}$ shows that the inhomogeneous microstructure contains grains with a mean size of $\sim 3.5 \mu \mathrm{m}$ forming long bands.

Figure 9 shows grain size distributions measured for specimens processed by 4 ECAP passes and subsequent creep testing at $373 \mathrm{~K}$. From Figs. 7-9 one can see that microstructure of specimens processed by 4 ECAP passes contains a mixture of a relatively high number of fine grains surrounded by and/or included in extremely large grains. Analyses of microstructure data for specimens processed by 4 ECAP passes and subsequent creep testing revealed that the highest number of large grains $(d>10 \mu \mathrm{m})$ was measured in SCI. However, the opposite result was found in the microstructure of polycrystalline Al (Fig. 9). Figures 8 and 9 also show that homogeneity of microstructures increases with increasing number of ECAP passes. The analysis of inhomogeneity in specimens after 4 ECAP passes and subsequent creep testing using CVa showed that the lowest value of $\mathrm{CV} a$ about 2.8 exhibited polycrystalline Al. The specimens of single crystals after 4 ECAP passes and subsequent creep testing exhibited higher values of $\mathrm{CV} a$ about 3.3 in SCII and about 4.7 in SCI in comparison with polycrystalline Al. The results in Figs. 7-9 demonstrate that microstructures of investigated specimens are highly inhomogeneous which may influence creep behaviour of ECAP processed specimens.

\subsection{Deformation behaviour}

The investigation of the surface of SCI tested at $373 \mathrm{~K}$ showed the formation of MSBs lying almost parallel to the shear plane of the last ECAP pass (Fig. 10a). It should be noted that this direction is identical to the direction of maximum shear stress during tensile testing. The MSBs were observed only in the neck area with a mean interband spacing of $\sim 150 \mu \mathrm{m}$.

Close inspection of Fig. 10a shows that MSBs consist of several thinner bands. The concentration of plastic deformation at the interfaces of MSB can be 

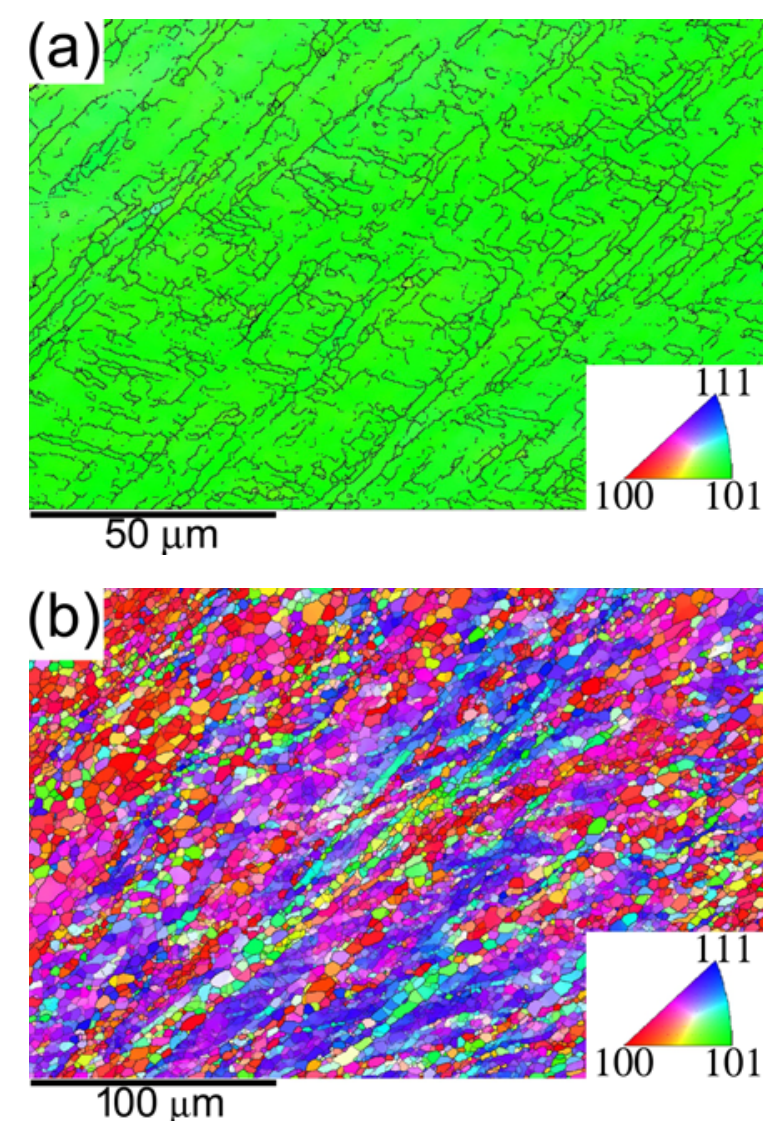

Fig. 8. The microstructure of polycrystalline $\mathrm{Al}$ (IPF maps, normal direction) after 1 and 4 ECAP passes and subsequent creep test at $373 \mathrm{~K}$ near the fracture (HAGBs are denoted by thick black line): (a) 1 and (b) 4 ECAP passes. The stress axis is horizontal for all micrographs.

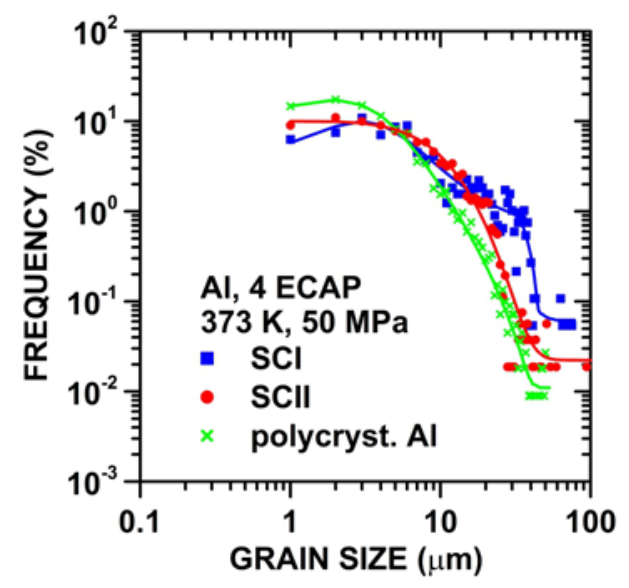

Fig. 9. The grain size distribution measured in specimens of pure $\mathrm{Al}$ after 4 ECAP passes and subsequent creep testing at $373 \mathrm{~K}$.

documented by deformation of marker lines (indicated by arrows) shifted along the stress axis. In the inte- rior of MSBs the deformation of marker lines was not observed.

On the surface of SCI processed by 4 ECAP passes, the MSBs lying near the shear plane of the last ECAP pass were observed (Fig. 10b). In the interior of the MSBs no significant bending of marker lines was observed. The mean interband spacing was $\sim 69 \mu \mathrm{m}$.

Figure $9 \mathrm{c}$ shows the surface of SCII processed by 1 ECAP pass. It is found that the MSBs on the surface of the specimen were inclined about $30^{\circ}$ with respect to the stress axis and at their interfaces the bending of marker lines was observed. The mean interband spacing was $\sim 32 \mu \mathrm{m}$.

The SCII after 4 ECAP passes and tested at $373 \mathrm{~K}$ exhibited the bending of marker lines at the interfaces of MSBs (not shown here) and also the displacement of marker lines at HAGBs situated in the interior of MSBs (Fig. 10d). The MSBs were approximately parallel to the stress axis with a mean interband spacing of $\sim 19 \mu \mathrm{m}$.

Inspection of Fig. 11a showed that the occurrence of MSBs significantly influenced deformation behaviour of polycrystalline $\mathrm{Al}$ processed by 1 ECAP pass. It is found that creep deformation of the $\mathrm{Al}$ polycrystalline specimen occurred primarily at the interfaces of MSBs. However, the deformation of polycrystalline $\mathrm{Al}$ processed by 4 ECAP passes is more homogeneous, and the marker lines exhibit a displacement at grain boundaries (Fig. 11b).

\section{Discussion}

In the present work, it was observed that ECAP processing of single crystals with two initial crystallographic orientations led to the formation of different inhomogeneous microstructures. In our previous works [12-17], it was found that the sample after 1 ECAP pass exhibited the highest creep resistance. This suggests that the highest creep resistance can be achieved in inhomogeneous ECAP-processed microstructure containing a high density of LAGBs but a lower density of HAGBs. Sklenička et al. [26, 27] performed numerous tensile creep tests of ECAPprocessed pure $\mathrm{Al}$ and reported the difference in creep resistance even after high numbers of ECAP passes. The present results show that the creep behaviour is influenced not only by the density of HAGBs but also by their distribution. It is observed that the microstructure inhomogeneity increases with the appearance of MSBs during creep testing (Figs. 6b and 7a). The different interband spacings, shifting of marker lines (scratches) at the interfaces, and preferential occurrence in the gauge length lead to the conclusion that the creep deformation is influenced not only by the initial state before ECAP processing but also by microstructures developed by ECAP processing. 


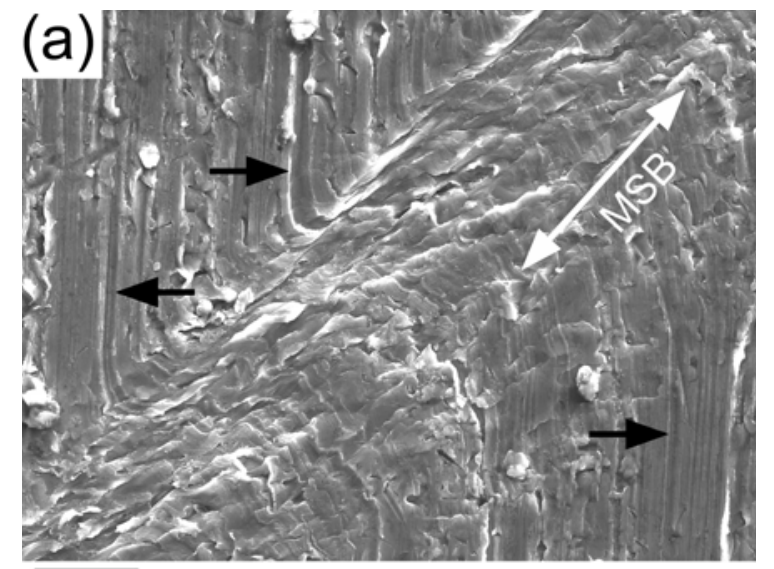

$\overline{20 \mu \mathrm{m}}$

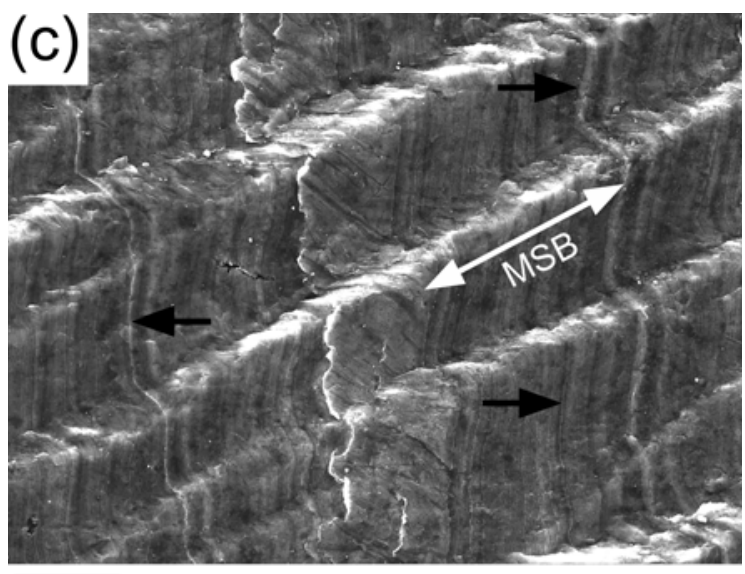

$\overline{20 \mu \mathrm{m}}$
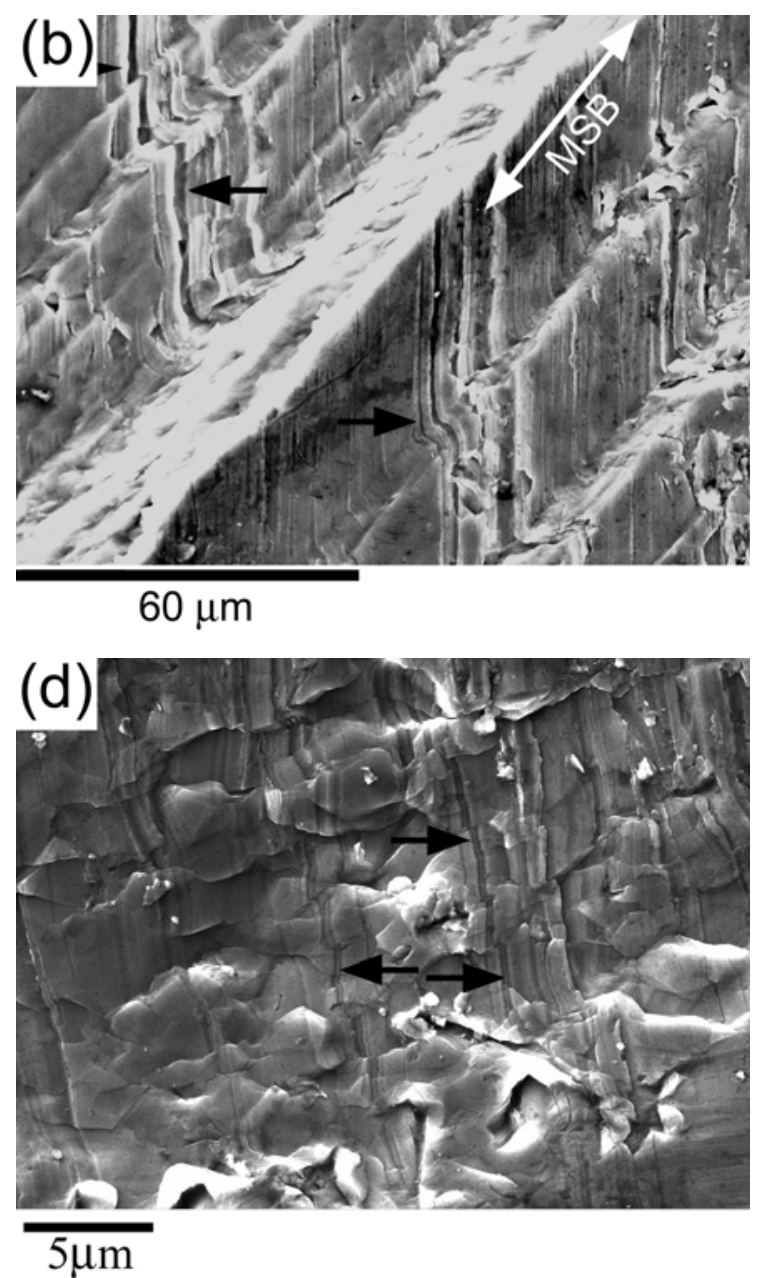

Fig. 10. The surface of single crystals processed by 1 and 4 ECAP passes: (a), (b) SCI and (c), (d) SCII. The microstructures processed by 1 ECAP pass are placed in the left column (a), (c). The stress axis is horizontal for all micrographs. Black arrows in the pictures denote the marker lines.

Microstructure analysis of specimens processed by ECAP showed increasing density of HAGBs with the increasing number of ECAP passes. The increase of HAGBs always led to the decrease of the creep resistance (Fig. 12). So the changes in creep behaviour after application of ECAP technique may be explained by the grain boundary-related deformation mechanism such as enhanced dynamic recovery of dislocations at HAGBs and/or by increased activity of grain boundary sliding (GBS).

Microstructure observations show that specimens after 4 ECAP passes contain higher densities of HAGBs which play a significant role in the creep behaviour.

The recent results show that creep behaviour of UFG materials can be significantly influenced either by GBS [15] or by the enhanced recovery of dislocations at HAGBs [10]. Both of these mechanisms occur easily when the grain size is finer than quasi-stationary spacing of LAGBs $[29,30] w_{\mathrm{qs}}=k_{\mathrm{w} \tau} b G / \tau=k_{\mathrm{w} \sigma}$ $b G / \sigma$ (where $\tau$ is resolved shear stress, $k_{\mathrm{w} \sigma}=M k_{\mathrm{w} \tau}$ is about 10 to $30, M=\sigma / \tau$ is Taylor factor, and $G$ is shear modulus at temperature $T$ ). In such finer grains, dislocations are stored in the grain boundaries but not in the interior of grains in the form of subgrains.

The observation in present work (Figs. 10, 11) revealed the displacement of marker lines at grain boundaries giving the qualitative evidence relating to an activity of GBS during creep of ECAP-processed Al. Sklenička et al. [15] investigated creep behaviour of UFG Al at $473 \mathrm{~K}$ and they concluded that contribution of GBS to the total creep strain in the UFG Al was only about $33 \%$. Certain quantitative data are also available for a tensile test of pure $\mathrm{Al}$ performed at room temperature and engineering strain rate $8.6 \times 10^{-3} \mathrm{~s}^{-1}[31]$. On the basis of deformation behaviour, it was suggested that GBS takes place in the initial stage of plastic deformation. In the later stages, intragranular dislocation slip becomes the primary deformation mechanism. This proposal is consistent with an earlier detailed experimental study [32] demonstrating that the largest number of grain 



$\overline{10 \mu \mathrm{m}}$

Fig. 11. The surface of polycrystalline $\mathrm{Al}$ processed by (a) 1 and (b) 4 ECAP passes. Black arrows in the pictures denote the marker lines. The stress axis is horizontal for all micrographs.

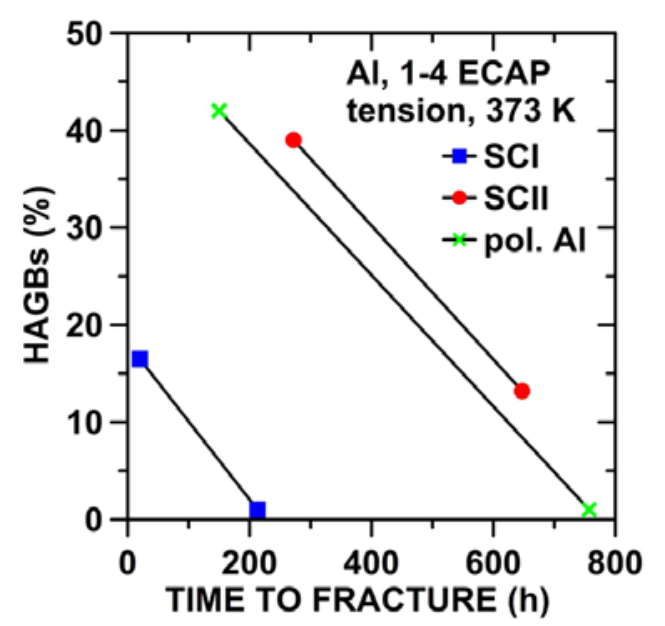

Fig. 12. Dependence of HAGBs on time to fracture of different initial states processed by 1 and 4 ECAP passes. boundaries begins to slip in early stages of creep exposure.

The stress dependences of minimum creep rates measured at $373 \mathrm{~K}$ show that the microstructure refinement due to the application of the method ECAP led to higher strength at given strain rate but to the decrease in stress exponent $n$ in comparison with CG state. Similar behaviour was observed during creep tests of pure $\mathrm{Cu}$ processed by ECAP up to 24 passes $[10,33]$. The systematic shift of the stress dependences to the higher strength with increasing number of ECAP passes was explained by increasing boundary misorientation, causing the densification of dislocation structure of LAGBs and the increase of high-angle boundary fraction. The change of stress exponent $n$ with decreasing applied stress (change of the slope of stress dependences) was characterized as a subsequent transition from hardening to softening through highangle boundaries whose fraction changes with increasing number of ECAP passes. This transition can be modelled by composite creep model $[34,35]$ because ECAP-processed microstructures are often inhomogeneous. The inhomogeneous microstructures containing both coarse and ultrafine grains were also found in present work.

Thus, composite approach, where the material is considered as composite, is adopted to explain the creep behaviour of the ECAP-processed Al using a volume fraction of the ultrafine-grained region, $f_{\mathrm{UFG}}$. The creep behaviour of microstructure containing CG regions and UFG regions can be described by isostrain composite as [10,33]:

$$
\begin{gathered}
\dot{\varepsilon}_{\mathrm{min}}=\dot{\varepsilon}_{\mathrm{CG}}=\dot{\varepsilon}_{\mathrm{UFG}} \\
\sigma\left(\dot{\varepsilon}_{\mathrm{min}}\right)=\left(1-f_{\mathrm{UFG}}\right) \sigma_{\mathrm{CG}}\left(\dot{\varepsilon}_{\mathrm{min}}\right)+f_{\mathrm{UFG}} \sigma_{\mathrm{UFG}}\left(\dot{\varepsilon}_{\mathrm{min}}\right) .
\end{gathered}
$$

The creep behaviour of fully UFG microstructure which is controlled by storage and dynamic recovery of free dislocations at high-angle boundaries is given by following equation [32]:

$$
\dot{\varepsilon}_{\text {min }}=A \frac{D_{\mathrm{gb}} G b}{k_{\mathrm{B}} T}\left(\frac{d}{b}\right)^{4}\left(\frac{\sigma}{G}\right)^{8},
$$

where $A$ is the numerical constant, $D_{\mathrm{gb}}$ is the grain boundary diffusion coefficient, $b$ is Burgers vector, $k_{\mathrm{B}}$ is Boltzmann constant, $G$ is shear modulus at temperature $T$, and $d$ is the grain size (estimated as $20 G b / \sigma)$. The numerical constant $A$ was calculated by setting the four fit parameters $f_{i}$ in $[13,34]$ equal to 0.23 and the dislocation interaction factor $\alpha$ equal to 0.2 . Equation (3) was adapted from classical dislocation theories of steady-state creep for CG materials to the case of UFG materials (see [34]). This equation is used in the situation where grain size is sufficiently small that new low-angle grain boundaries 
Table 2. Material parameters used in the modelling of creep behaviour

\begin{tabular}{lcc}
\hline Parameter & $\mathrm{Al}$ & Reference \\
\hline Boundary dif. coefficient, $D_{\mathrm{gb}}\left(\mathrm{m}^{2} \mathrm{~s}^{-1}\right)$ & $1.7 \times 10^{-16}$ & {$[28]$} \\
Lattice dif. coefficient, $D_{\mathrm{l}}\left(\mathrm{m}^{2} \mathrm{~s}^{-1}\right)$ & $2.16 \times 10^{-24}$ & {$[28]$} \\
Burgers vector, $b(\mathrm{~m})$ & $2.86 \times 10^{-10}$ & {$[28]$} \\
Shear modulus at $373 \mathrm{~K}, G(\mathrm{MPa})$ & $2.44 \times 10^{4}$ & {$[28]$} \\
Poisson's ratio, $u$ & 0.34 & \\
Taylor factor, $M$ & 3.6 & \\
\hline
\end{tabular}

are not formed in the grain interior. Thus the grain boundaries limit the mean free dislocation path and the dislocations easily recover at high-angle boundaries.

The formula used for description of the quasi-stationary deformation resistance of fully $\mathrm{CG} \mathrm{Al}$ where the dynamic recovery is controlled by LAGBs is following $[13,14,34]$ :

$$
\begin{aligned}
& \dot{\varepsilon}_{\text {min }}=A \frac{D_{1} G b}{k_{\mathrm{B}} T}\left(\frac{\sigma}{G}\right)^{3} \exp (B \sigma), \\
& A=1, B=\frac{k_{\mathrm{h}} b^{3}}{M \theta_{\text {lab }} k_{\mathrm{B}} T},
\end{aligned}
$$

where $D_{1}$ is the lattice diffusion coefficient, $B$ decreases as the average subgrain misorientation increases with strain. $B$ was estimated by setting $k_{\mathrm{h}}=7$. The material parameters used for modelling curves are shown in Table 2. One can see that Eq. (4) has two parts. The part in front of the exponential function represents the natural creep law. This part guarantees the right magnitude of minimum creep rate for CG material if the exponential part goes near 1 at low stresses about $10^{-5} \mathrm{G}[36]$. The second part of Eq. (4) describes power-law breakdown. This part characterizes thermally activated glide where the dislocation movement is so fast that an enormous increase in creep rates occurs.

Figure 13 demonstrates that the creep resistance after ECAP processing is associated with the increase of HAGBs and the reduction of grain size. Blum et al. [34] suggested that the increase of the average misorientation leads to higher strength thus the stress dependence for ECAP-processed specimens is shifted to higher stresses. However, the reduction of grain size near quasi-stationary spacing $w_{\mathrm{qs}}$ promotes the thermal recovery of dislocations at HAGBs which leads to the decrease of stress exponent $n$.

Nevertheless, the microstructure inhomogeneity of ECAP-processed specimens led to the different creep behaviour (Fig. 13). The 4 ECAP passed samples containing fine-grained structure showed a decrease of minimum creep rate as delineated by the solid blue curve in Fig. 13 in comparison with CG polycrystalline $\mathrm{Al}$ (dashed red curve in Fig. 13). This creep behaviour can be modelled by Eq. (2) where a certain fraction of UFG regions is considered which leads to a lower

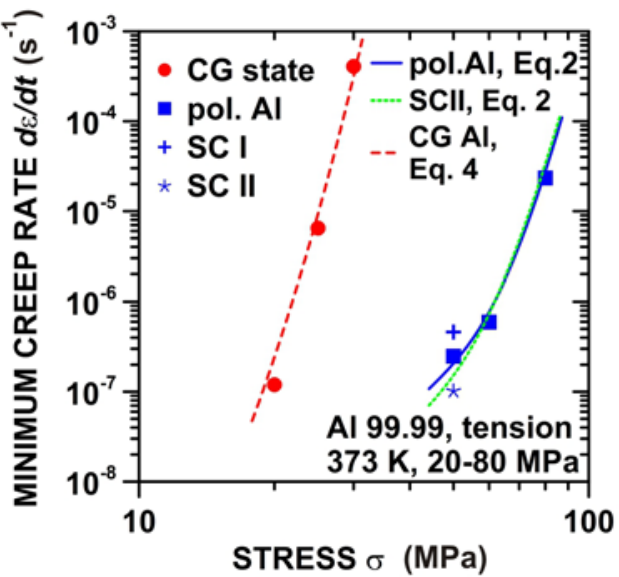

Fig. 13. Creep results for Al processed by 4 ECAP passes measured at $373 \mathrm{~K}$ in comparison to $\mathrm{CG}$ state and model curves. The volume fraction of the ultrafine-grained region $\left(f_{\mathrm{UFG}}\right)$ in polycrystalline $\mathrm{Al}$ was estimated $\sim 0.35$ and $\sim 0.2$ in SCII (estimated from Figs. $7-9$ ).

activity of storage and recovery of free dislocations at HAGBs and causes a decrease of minimum creep rate (dotted green line in Fig. 13).

But the results showed that creep behaviour is influenced not only by the volume fraction of UFG regions but also by an inhomogeneous distribution of HAGBs. The microstructure of SCI also contained a low value of UFG regions (Fig. 7b), but SCI specimen showed higher minimum creep rate in comparison with UFG polycrystalline Al. This suggests that creep behaviour of SCI specimen is probably influenced by additional creep mechanism.

The surface of creep specimens and microstructure investigation revealed the formation of MSBs. It can be suggested that the cooperative sliding of grains occurring at interfaces of MSBs may accelerate creep deformation and lead to the faster minimum creep rate. Thus creep behaviour of ECAP-processed specimens can also be influenced by the enhanced activity of GBS.

\section{Conclusions}

It was found that the creep behaviour of $\mathrm{Al}$ de- 
pends significantly on the number of ECAP passes. ECAP-processed $\mathrm{Al}$ exhibited a decrease of creep resistance with increasing number of ECAP passes but creep resistance was higher in comparison with CG state. However, stress dependences of minimum creep rate showed a significant decrease of stress sensitivity in the ECAP-processed specimens.

It was suggested that the creep behaviour of ECAP-processed Al could be explained by the synergetic effect of enhanced recovery of dislocations at HAGBs in grains with $d \sim w_{\text {qs }}$ and intragranular dislocation processes in $\mathrm{CG}$ regions where recovery of dislocations is significantly influenced by LAGBs. The results show that different creep properties are caused by inhomogeneity of ECAP microstructure and creep behaviour depends mainly on the frequency of UFG grains that fulfilled the condition $d \sim w_{\mathrm{qs}}$ but can also be influenced by the formation of MSBs.

\section{Acknowledgements}

This research was carried out under the project CEITEC 2020 (LQ1601) with financial support from the Ministry of Education, Youth and Sports of the Czech Republic under the National Sustainability Programme II. This work was also supported by a Grant-in-Aid for Scientific Research (S) from the MEXT, Japan (No. 26220909). The authors thank Dr P. Seda for the preparation of Al single crystals.

\section{References}

[1] Valiev, R. Z., Islamgaliev, R. K., Alexandrov, I. V.: Prog. Mater. Sci., 45, 2000, p. 103. doi:10.1016/S0079-6425(99)00007-9

[2] Valiev, R. Z., Korznikov, A. V., Mulyukov, R. R.: Mater. Sci. Eng. A, 168, 1993, p. 141. doi:10.1016/0921-5093(93)90717-S

[3] Iwahashi, Y., Horita, Z., Nemoto, M., Langdon, T. G.: Acta Mater., 46, 1998, p. 3317. doi:10.1016/S1359-6454(97)00494-1

[4] Saito, Y., Utsunomiya, H., Tsuji, N., Sakai, T.: Acta Mater., 47, 1999, p. 579. doi:10.1016/S1359-6454(98)00365-6

[5] Fukuda, Y., Oh-ishi, K., Furukawa, M., Horita, Z., Langdon, T. G.: Acta Mater., 52, 2004, p. 1387. doi:10.1016/j.actamat.2003.11.028

[6] Hafok, H., Pippan, R.: Mater. Sci. Forum, 550, 2007, p. 277. doi:10.4028/www.scientific.net/MSF.550.277

[7] Grosdidier, T., Fundenberger, J-J., Goran, D., Bouzy, E., Suwas, S., Skrotzki, W., Tóth, L. S.: Scripta Mater., 59, 2008, p. 1087. doi:10.1016/j.scriptamat.2008.07.032

[8] Sedá, P., Ostapovets, A., Jäger, A., Lejček, P.: Philosophical Magazine, 92, 2012, p. 1223. doi:10.1080/14786435.2011.643249

[9] Miyamoto, H., Fushimi, J., Mimaki, T., Vinogradov, A., Hashimoto, S.: Mater. Sci. Eng. A, 405, 2005, p. 221. doi:10.1016/j.msea.2005.05.091
[10] Blum, W., Li, Y. J., Zhang, Y., Wang, J. Y.: Mater. Sci. Eng. A, 528, 2011, p. 8621. doi:10.1016/j.msea.2011.08.010

[11] Kawasaki, M., Sklenička, V., Langdon, T. G.: Kovove Mater., 49, 2011, p. 75. doi:10.4149/km_2011_1_75

[12] Sklenička, V., Dvořák, J., Svoboda, M., Král, P., Vlach, B.: Mater. Sci. Forum, 482, 2005, p. 83. doi:10.4028/www.scientific.net/MSF.482.83

[13] Blum, W., Dvořák, J., Král, P., Eisenlohr, P., Sklenička, V.: Mater. Sci. Eng. A, 590, 2014, p. 423. doi:10.1016/j.msea.2013.10.022

[14] Blum, W., Dvořák, J., Král, P., Petrenec, M., Eisenlohr, P., Sklenička, V.: Phil. Mag., 95, 2015, p. 3696. doi:10.1080/14786435.2015.1096025

[15] Sklenicka, V., Dvorak, J., Kral, P., Stonawska, Z., Svoboda, M.: Mater. Sci. Eng. A, 410-411, 2005, p. 408. doi:10.1016/j.msea.2005.08.099

[16] Král, P., Dvořák, J., Sedá, P., Jäger, A., Sklenička, V.: Rev. Adv. Mater. Sci., 31, 2012, p. 138.

[17] Sklenicka, V., Dvorak, J., Kral, P., Svoboda, M., Kvapilova, M., Kopilov, V. I., Nikulin, S. A., Dobatkin, S. V.: Acta Physica Polonica A, 122, 2012, p. 485. doi:10.12693/APhysPolA.122.485

[18] Kral, P., Svoboda, M., Dvorak, J., Kvapilova, M., Sklenicka, V.: Acta Physica Polonica A, 122, 2012, p. 457. doi:10.12693/APhysPolA.122.457

[19] Král, P., Dvořák, J., Sklenička, V.: Mater. Sci. Forum, 584-586, 2008, p. 846. doi:10.4028/www.scientific.net/MSF.584-586.846

[20] Sklenička, V., Dvořák, J., Kvapilová, M., Svoboda, M., Král, P., Saxl, I., Horita, Z.: Mater. Sci. Forum, 539543, 2007, p. 2904. doi:10.4028/www.scientific.net/MSF.539-543.2904

[21] Grabovetskaya, G. P., Ivanov, K. V., Kolobov, Y. R.: Ann. Chim. Sci. Mat., 27, 2002, p. 89.

[22] Kawasaki, M., Beyerlein, I. J., Vogel, S. C., Langdon, T. G.: Acta Mater., 56, 2008, p. 2307. doi:10.1016/j.actamat.2008.01.023

[23] Li, Y. J., Valiev, R., Blum, W.: Mater. Sci. Eng. A, 410-411, 2005, p. 451. doi:10.1016/j.msea.2005.08.107

[24] Ilucova, L., Saxl, I., Svoboda, M., Sklenicka, V., Kral, P.: Image Anal. Stereol., 26, 2007, p. 37. doi:10.5566/ias.v26.p37-43

[25] Saxl, I., Sklenička, V., Ilucová, L., Svoboda, M., Král, P., Dvořák, J.: Rev. Adv. Mater. Sci., 25, 2010, p. 233.

[26] Sklenička, V., Král, P., Ilucová, L., Saxl, I., Dvořák, J., Svoboda, M.: Mat. Sci. Forum, 503-504, 2006, p. 245. doi:10.4028/www.scientific.net/MSF.503-504.245

[27] Král, P., Dvořák, J., Kvapilová, M., Sklenička, V., Svoboda, M.: Acta Metall. Slovaca, 13, 2007, p. 289.

[28] Frost, H. J., Ashby, M. F.: Deformation-Mechanism Maps. Oxford, Pergamon Press 1982.

[29] Raj, S. V., Pharr, G. M.: Mater. Sci. Eng., 81, 1986, p. 217. doi:10.1016/0025-5416(86)90265-X

[30] Nes, E.: Prog. in Mater. Sci., 41, 1998, p. 129. doi:10.1016/S0079-6425(97)00032-7

[31] Ivanov, K. V., Naydenkin, E. V., Scripta Mater., 66, 2016, p. 511. doi:10.1016/j.scriptamat.2011.12.039

[32] Sklenička, V., Cadek, J.: Kovove Mater., 6, 1968, p. 81.

[33] Blum, W., Li, Y. J., Zhang, Y., Wang, J. T.: Mater. Sci. Eng. A, 528, 2011, p. 8621. $\underline{\text { doi:10.1016/j.msea.2011.08.010 }}$ 
[34] Blum, W., Zeng, X. H.: Acta Mater., 57, 2009, p. 1966. doi:10.1016/i.actamat.2008.12.041

[35] Blum, W., Rosen, A., Cegielska, A., Martin, J. T.: Acta Metall., 37, 1989, p. 2439. doi:10.1016/0001-6160(89)90041-2
[36] Blum, W.: Plastic Deformation and Fracture of Materials.Volume 6. Materials Science and Technology. Eds.: Mughrobi, H., Cahn, R. W., Haasen, P., Kramer, E. J. Weinheim, VCH Verlagsgesellschaft 1993. 